\title{
A Highly Efficient Synthesis of Optically Active Ferrocenylethylamines via Hydride Reduction of Chiral Ferrocenylketimines
}

\author{
Hengyu Qian, ${ }^{a, b}$ Shihai Yan, ${ }^{c}$ Xiuling Cui, ${ }^{*, a}$ Chao $\mathrm{Pi}^{a}{ }^{a}$ Cheng Liu, ${ }^{a}$ and Yangjie $\mathrm{Wu}^{*, a}$ \\ ${ }^{a}$ Henan Key Laboratory of Chemical Biology and Organic Chemistry, Key Laboratory of Applied Chemistry of \\ Henan Universities, Department of Chemistry, Zhengzhou University, Zhengzhou, Henan 450052, China \\ ${ }^{b}$ Henan Key Laboratory of Surface \& Interface Science, School of Material \& Chemical Engineering, Zhengzhou \\ University of Light Industry, Zhengzhou, Henan 450002, China \\ ${ }^{c}$ Lab of Biofuel, Institute of Bioenergy and Bioprocess Technology, Chinese Academy of Sciences, Qingdao, Shan- \\ dong 266101, China
}

\begin{abstract}
Due to using $(R)$ - or $(S)$ - $\alpha$-methylbenzylamine as a chiral auxiliary, and low-temperature regime for reduction of the intermediate ferrocenyl-mono- or 1,1'-bis-ketimines, the corresponding secondary mono- or 1,1'-bis-amines were prepared with high diastereoselectivity. Removal of the $\alpha$-methylbenzyl group afforded the optically active primary mono- and bis-ferrocenylethylamines in high yields. The absolute configuration of $(R, R)-\mathbf{3 a}$ and $(S, S)$-3b was determined by X-ray single crystal diffraction.
\end{abstract}

Keywords chiral, reduction, ferrocenylketimine, diastereoselectivity, ferrocenylethylamine

\section{Introduction}

Chiral ferrocene derivatives are the most useful ligands in asymmetric synthesis, ${ }^{[1]}$ among which the ferrocene ligands with planar chirality have increased exponentially due to their excellent catalytic results. ${ }^{[2]}$ The tertiary $\alpha$-ferrocenylalkylamines were usually used as a precursor for the synthesis of ferrocenes displaying planar chirality. ${ }^{[2 b, 3]}$ Diastereoselective addition of organolithium reagent to the $\mathrm{C}=\mathrm{N}$ bond of chiral ferrocenylimines derivatives, followed by cleavage of the chiral auxiliary portion, provided a useful method. ${ }^{[4]}$ Such methodology is less tolerable to functional groups. Moreover, the protection of inert gas and low temperature are required since the organolithium reagent is highly active and sensitive to the moisture and $\mathrm{O}_{2}$ in air. In contrast, sodium borohydride is an inexpensive, easy to handle and environmentally friendly reducing reagent for chemoselective reduction of ketimines. ${ }^{[5]}$ Herein, we report a convenient route to synthesize the optically active mono- and bis-ferrocenylethylamines via highly diastereoselective reduction of ketimine with sodium borohydride and the subsequent cleavage of $\alpha$-methylbenzyl group by $\mathrm{Pd} / \mathrm{C}$ and ammonium formate as $\mathrm{H}_{2}$ resources. This methodology was based on the previously described research ${ }^{[5 a]}$ devoted to diastereoselective hydride reduction of the ferrocenylketimine, which was improved by condensation of the corresponding ketones and $(R)$ - or $(S)$ - $\alpha$-methylbenzylamine in dry toluene in the presence of active $\mathrm{Al}_{2} \mathrm{O}_{3}$, and reduction of the ketimines to provide the corresponding amine with complete enantiopurity.

\section{Experimental}

\section{General}

Melting points were measured on an $\mathrm{X}_{4}-1$ microscopic apparatus and were uncorrected. Elemental analyses were determined with a Carlo Erba 1160 elemental analyzer. ${ }^{1} \mathrm{H}$ and ${ }^{13} \mathrm{C}$ NMR spectra were recorded on a Bruker DPX 400 spectrometer, using $\mathrm{CDCl}_{3}$ as solvent and TMS as an internal reference standard. IR spectra were recorded on a Bruker-Vector 22 spectrophotometer. Optical rotations were determined at $589 \mathrm{~nm}$ on a Perkin-Elmer 341 polarimeter at $20{ }^{\circ} \mathrm{C}$. All solvents were dried according to the standard methods. $(R)$-, $(S)$ - $\alpha$-methylbenzylamine (ee 99.5\%) and sodium borohydride were purchased from ACROS and used without purification.

\section{Synthesis of compounds $(R, R)-3 \mathrm{a}$ and $(S, S)-3 \mathrm{~b}$}

Acetylferrocene $(2.28 \mathrm{~g}, 10 \mathrm{mmol})$ and $(R)$ - or $(S)$ $\alpha$-methylbenzylamine $(1.452 \mathrm{~g}, 12 \mathrm{mmol})$ were dis-

* E-mail: wyj@zzu.edu.cn, cuixl@zzu.edu.cn; Tel.: 0086-0371-67767753; Fax: 0086-0371-67767753

Received March 17, 2013; accepted June 5, 2013; published online July 5, 2013.

Supporting information for this article is available on the WWW under http://dx.doi.org/10.1002/cjoc.201300211 or from the author. 
solved in dry toluene in the presence of active $\mathrm{Al}_{2} \mathrm{O}_{3}$, then refluxed for $20 \mathrm{~h}$. The mixture was filtered and the filtrate was evaporated under reduced pressure. The unstable crude ferrocenylketimines $\mathbf{2}$ were obtained and reduced with sodium borohydride $(1.85 \mathrm{~g}, 50 \mathrm{mmol})$, which was added over $2 \mathrm{~h}$ at $-15{ }^{\circ} \mathrm{C}$ in methanol. The mixture was stirred for $8 \mathrm{~h}$, then evaporated to dryness, extracted with ether and dried over $\mathrm{Na}_{2} \mathrm{SO}_{4}$. The residue was isolated by flash chromatography over silica gel (chloroform/ethyl acetate, $V: V=5: 1)$. $(R, R)-3 \mathbf{a}: 2.74$ g $(82 \%)$, orange solid, m.p. $65-66{ }^{\circ} \mathrm{C},[\alpha]_{\mathrm{D}}^{20}-43.7(c$ 1.2, benzene); ${ }^{1} \mathrm{H} \mathrm{NMR}\left(\mathrm{CDCl}_{3}, 400 \mathrm{MHz}\right) \delta: 1.23$ (d, $J=6.5 \mathrm{~Hz}, 3 \mathrm{H}), 1.40(\mathrm{~d}, J=6.6 \mathrm{~Hz}, 3 \mathrm{H}), 3.33(\mathrm{q}, J=$ $6.6 \mathrm{~Hz}, 1 \mathrm{H}), 3.82(\mathrm{q}, J=6.7 \mathrm{~Hz}, 1 \mathrm{H}), 4.07(\mathrm{~s}, 5 \mathrm{H}), 4.02$, $4.11,4.12,4.16$ (each s, 4H), 7.26-7.36 (m, 5H); ${ }^{13} \mathrm{C}$ $\mathrm{NMR}\left(\mathrm{CDCl}_{3}, 100 \mathrm{MHz}\right) \delta: 22.7,25.5,49.2,55.1,64.8$, 66.9, 67.4, 68.1, 68.4, 93.3, 126.7, 126.7, 128.4, 146.2; IR (KBr) $v: 3020,1108,1020,875,500 \mathrm{~cm}^{-1}$. Anal. calcd for $\mathrm{C}_{20} \mathrm{H}_{23} \mathrm{FeN}$ : C 72.07, H 6.91, N 4.20; found $\mathrm{C}$ 72.10, H 6.91, N 4.21. (S,S)-3b: $2.83 \mathrm{~g}(85 \%)$, orange solid, m.p. $65-66{ }^{\circ} \mathrm{C},[\alpha]_{\mathrm{D}}^{20}+43.2$ (c 1.2, benzene); ${ }^{1} \mathrm{H} \mathrm{NMR}\left(\mathrm{CDCl}_{3}, 400 \mathrm{MHz}\right) \delta: 1.24(\mathrm{~d}, J=6.8 \mathrm{~Hz}, 3 \mathrm{H})$, 1.39 (d, $J=6.8 \mathrm{~Hz}, 3 \mathrm{H}), 3.33$ (q, $J=6.7 \mathrm{~Hz}, 1 \mathrm{H}), 3.81$ $(\mathrm{q}, J=6.6 \mathrm{~Hz}, 1 \mathrm{H}), 4.06(\mathrm{~s}, 5 \mathrm{H}), 4.02,4.11,4.13,4.16$ $(\mathrm{s}, 4 \mathrm{H}), 7.24-7.36(\mathrm{~m}, 5 \mathrm{H}) ;{ }^{13} \mathrm{C} \mathrm{NMR}\left(\mathrm{CDCl}_{3}, 100\right.$ $\mathrm{MHz}) \delta: 22.8,25.5,49.3,55.2,64.9,66.9,67.5,68.2$, 68.4, 93.4, 126.7, 126.7, 128.4, 146.3; IR (KBr) v: 3021, $1100,1020,870,510 \mathrm{~cm}^{-1}$. Anal. calcd for $\mathrm{C}_{20} \mathrm{H}_{23} \mathrm{FeN}$ : C 72.07, H 6.91, N 4.20; found C 72.11, H 6.92, N 4.20.

\section{Synthesis of compounds $(R)-4 a$ and $(S)-4 b$}

Ammonium formate (252 mg, $4 \mathrm{mmol}$ ) and $5 \% \mathrm{Pd} / \mathrm{C}$ (20 mg) were added to the solution of compounds $(R, R)-\mathbf{3 a}$ or $(S, S)-\mathbf{3 b}(333 \mathrm{mg}, 1 \mathrm{mmol})$ in dry methanol, respectively. After stirred for $3 \mathrm{~h}$ at $65{ }^{\circ} \mathrm{C}$, the mixture was filtered and concentrated in vacuum. The crude products $(R)-\mathbf{4 a}$ and $(S)-\mathbf{4 b}$ were separated by chromatography on silica gel (chloroform/ethyl acetate, $V: V$ $=4: 1)$. $(R)-4 \mathbf{a}: 206 \mathrm{mg}(90 \%)$, orange oil, $[\alpha]_{\mathrm{D}}^{20}$ -26.8 (c 1.04, benzene); ${ }^{1} \mathrm{H} \mathrm{NMR}\left(\mathrm{CDCl}_{3}, 400 \mathrm{MHz}\right) \delta$ : $1.34(\mathrm{~d}, J=6.6 \mathrm{~Hz}, 3 \mathrm{H}), 1.77(\mathrm{br}, 2 \mathrm{H}), 3.80$ (q, $J=6.5$ $\mathrm{Hz}, 1 \mathrm{H}), 4.11-4.15(\mathrm{~m}, 4 \mathrm{H}), 4.15(\mathrm{~s}, 5 \mathrm{H}) ;{ }^{13} \mathrm{C} \mathrm{NMR}$ $\left(\mathrm{CDCl}_{3}, 100 \mathrm{MHz}\right) \delta: 24.7,45.9,65.6,65.7,67.3,67.4$, 68.3, 96.3; IR (KBr) v: 3445, 3060, 2970, 1560, 1108, $1010,805 \mathrm{~cm}^{-1}$. Anal. calcd for $\mathrm{C}_{12} \mathrm{H}_{15} \mathrm{FeN}$ : C 62.88, $\mathrm{H}$ 6.55, N 6.11; found C 62.52, H 6.81, N 6.21. (S)-4b: $211 \mathrm{mg}(92 \%)$, orange oil, $[\alpha]_{\mathrm{D}}^{20}+26.2$ (c 1.04, benzene) [lit. ${ }^{[3 \mathrm{~b}]}[\alpha]_{\mathrm{D}}^{20}+26.7$ (c 1.04, benzene)]; ${ }^{1} \mathrm{H}$ $\operatorname{NMR}\left(\mathrm{CDCl}_{3}, 400 \mathrm{MHz}\right) \delta: 1.35(\mathrm{~d}, J=6.5 \mathrm{~Hz}, 3 \mathrm{H})$, 1.79 (br, 2H), 3.80 (q, $J=6.5 \mathrm{~Hz}, 1 \mathrm{H}), 4.11-4.18$ (m, $4 \mathrm{H}), 4.15(\mathrm{~s}, 5 \mathrm{H}) ;{ }^{13} \mathrm{C} \mathrm{NMR}\left(\mathrm{CDCl}_{3}, 100 \mathrm{MHz}\right) \delta: 24.6$, 46.0, 65.6, 65.8, 67.3, 67.4, 68.2, 96.2; IR (KBr) v: 3450, $3050,2970,1560,1105,1010,800 \mathrm{~cm}^{-1}$. Anal. calcd for $\mathrm{C}_{12} \mathrm{H}_{15} \mathrm{FeN}$ : C 62.88, H 6.55, N 6.11; found $\mathrm{C} 62.49, \mathrm{H}$ 6.63, N 6.19.

\section{Synthesis of compounds $9 \mathrm{a}, 9 \mathrm{~b}$}

Diacetylferrocene $(2.70 \mathrm{~g}, 10 \mathrm{mmol})$ and $(R)$ - or $(S)$ - $\alpha$-methylbenzylamine $(2.90 \mathrm{~g}, 24 \mathrm{mmol})$ were dissolved in dry toluene in the presence of active $\mathrm{Al}_{2} \mathrm{O}_{3}$, then refluxed for $20 \mathrm{~h}$. The mixture was filtered and the filtrate was evaporated under reduced pressure. The crude ferrocenylketimines $\mathbf{8 a}, \mathbf{8 b}$ were obtained and reduced with sodium borohydride (3.7 g, $100 \mathrm{mmol})$ without isolation. Sodium borohydride was added in portion over $2 \mathrm{~h}$ at $-15{ }^{\circ} \mathrm{C}$ in methanol. The mixture was stirred for $8 \mathrm{~h}$, then evaporated to dryness, extracted with ether and dried over $\mathrm{Na}_{2} \mathrm{SO}_{4}$. The residue was purified by flash chromatography over silica gel (chloroform/ethyl acetate, $V: V=4: 1)$. $(R, R, R, R)-9 \mathbf{a}: 3.98 \mathrm{~g}$ $(83 \%)$, orange oil, $[\alpha]_{\mathrm{D}}^{20}-72.1$ (c 1.0 , benzene); ${ }^{1} \mathrm{H}$ NMR $\left(\mathrm{CDCl}_{3}, 400 \mathrm{MHz}\right) \delta: 1.19(\mathrm{~d}, J=6.4 \mathrm{~Hz}, 3 \mathrm{H})$, 1.33 (d, $J=6.4 \mathrm{~Hz}, 3 \mathrm{H}), 3.28$ (q, $J=6.6 \mathrm{~Hz}, 1 \mathrm{H}), 3.76$ $(\mathrm{q}, J=6.5 \mathrm{~Hz}, 1 \mathrm{H}), 3.90-4.10(\mathrm{~m}, 4 \mathrm{H}), 7.23-7.32(\mathrm{~m}$, $5 \mathrm{H}) ;{ }^{13} \mathrm{C} \mathrm{NMR}\left(\mathrm{CDCl}_{3}, 100 \mathrm{MHz}\right) \delta: 22.7,25.4,49.2$, 55.2, 65.4, 67.8, 68.3, 68.7, 72.9, 126.6, 126.7, 128.4, 128.5; IR (KBr) v: 3025, 2964, 1629, 1452, 1368, 762, $702 \mathrm{~cm}^{-1}$. Anal. calcd for $\mathrm{C}_{30} \mathrm{H}_{36} \mathrm{FeN}_{2}$ : C 75.00, H 7.50, $\mathrm{N}$ 5.83; found C 75.32, H 7.61, N 5.98. $(S, S, S, S)-9 \mathbf{b}$ : $4.03 \mathrm{~g}(84 \%)$, orange oil, $[\alpha]_{\mathrm{D}}^{20}+71.5$ (c 1.0, benzene); ${ }^{1} \mathrm{H} \mathrm{NMR}\left(\mathrm{CDCl}_{3}, 400 \mathrm{MHz}\right) \delta: 1.20(\mathrm{~d}, J=5.4 \mathrm{~Hz}, 3 \mathrm{H})$, 1.32 (d, $J=6.5 \mathrm{~Hz}, 3 \mathrm{H}), 3.28$ (q, $J=6.5 \mathrm{~Hz}, 1 \mathrm{H}), 3.78$ $(\mathrm{q}, J=6.4 \mathrm{~Hz}, 1 \mathrm{H}), 3.91-4.08(\mathrm{~m}, 4 \mathrm{H}), 7.22-7.32(\mathrm{~m}$, $5 \mathrm{H}) ;{ }^{13} \mathrm{C} \mathrm{NMR}\left(\mathrm{CDCl}_{3}, 100 \mathrm{MHz}\right) \delta: 22.7,25.4,49.3$, 55.2, 65.5, 67.8, 68.3, 68.7, 72.8, 126.6, 126.7, 126.8, 128.4; IR (KBr) v: 3040, 2950, 1635, 1451, 1360, 768, $690 \mathrm{~cm}^{-1}$. Anal. calcd for $\mathrm{C}_{30} \mathrm{H}_{36} \mathrm{FeN}_{2}$ : C 75.00, H 7.50, N 5.83; found C 75.45, H 7.59, N 5.95.

\section{Synthesis of compounds 10a, 10b}

Ammonium formate (504 mg, $8 \mathrm{mmol}$ ) and $5 \% \mathrm{Pd} / \mathrm{C}$ (40 mg) were added to the solution of compounds $9 \mathbf{a}$, 9b (480 mg, $1 \mathrm{mmol})$ in dry methanol. After stirred for $3 \mathrm{~h}$ at $65{ }^{\circ} \mathrm{C}$, the mixture was filtered and concentrated in vacuum. The crude products $\mathbf{1 0 a}, \mathbf{1 0 b}$ were purified by chromatography on silica gel (chloroform/ethyl acetate, $V: V=4: 1)$. $(R, R)-10 a: 207 \mathrm{mg}(76 \%)$, orange oil, $[\alpha]_{\mathrm{D}}^{20}-32.1\left(c \quad 0.01, \mathrm{CHCl}_{3}\right)\left[\right.$ lit. $^{[6]}[\alpha]_{\mathrm{D}}^{20}-33.3(c$ $\left.\left.0.01, \mathrm{CHCl}_{3}\right)\right] ;{ }^{1} \mathrm{H} \mathrm{NMR}\left(\mathrm{CDCl}_{3}, 400 \mathrm{MHz}\right) \delta: 2.18(\mathrm{~d}$, $J=6.5 \mathrm{~Hz}, 3 \mathrm{H}), 3.11(\mathrm{q}, J=6.8 \mathrm{~Hz}, 1 \mathrm{H}), 4.24-4.81(\mathrm{~m}$, $4 \mathrm{H}) ;{ }^{13} \mathrm{C} \mathrm{NMR}\left(\mathrm{CDCl}_{3}, 100 \mathrm{MHz}\right) \delta: 30.9,45.2,70.0$, 70.3, 70.5, 73.3; IR (KBr) v: 3354, 3020, 2970, 1580, $760 \mathrm{~cm}^{-1}$. Anal. calcd for $\mathrm{C}_{14} \mathrm{H}_{20} \mathrm{FeN}_{2}$ : C 61.76, H 7.35, $\mathrm{N}$ 10.29; found $\mathrm{C}$ 61.38, H 7.51, N 10.18. $(S, S)-\mathbf{1 0 b}$ : $212 \mathrm{mg}(78 \%)$, orange oil, $[\alpha]_{\mathrm{D}}^{20}+32.9$ (c 0.01 , $\left.\mathrm{CHCl}_{3}\right) ;{ }^{1} \mathrm{H} \mathrm{NMR}\left(\mathrm{CDCl}_{3}, 100 \mathrm{MHz}\right) \delta: 2.18(\mathrm{~d}, J=6.6$ $\mathrm{Hz}, 3 \mathrm{H}), 3.12$ (q, $J=6.9 \mathrm{~Hz}, 1 \mathrm{H}), 4.23-4.82(\mathrm{~m}, 4 \mathrm{H})$; ${ }^{13} \mathrm{C} \mathrm{NMR}\left(\mathrm{CDCl}_{3}, 400 \mathrm{MHz}\right) \delta: 30.9,45.8,70.2,70.5$, 70.6, 73.4; IR (KBr) v: 3360, 3010, 2950, 1585, 740 $\mathrm{cm}^{-1}$. Anal. calcd for $\mathrm{C}_{14} \mathrm{H}_{20} \mathrm{FeN}_{2}: \mathrm{C} 61.76, \mathrm{H} 7.35, \mathrm{~N}$ 10.29; found C 61.32, H 7.58, N 10.07.

\section{Results and Discussion}

As shown in Scheme 1, the condensation of acetylferrocene 1 with $(R)$ - and $(S)$ - $\alpha$-methylbenzylamine 
afforded the chiral ketimines $\mathbf{2 a}, \mathbf{2 b} .{ }^{[5 \mathrm{a}]}$ The ketimines $\mathbf{2 a}, \mathbf{2 b}$ were used directly for the next step without purification. Subsequent reduction of the ketimines $\mathbf{2 a}, \mathbf{2 b}$ with sodium borohydride at $-15{ }^{\circ} \mathrm{C}$ in dry methanol gave the chiral secondary amines $\mathbf{3 a}, \mathbf{3 b}$ in good yields (3a: 82\%; 3b: 85\%) and with excellent diastereoselectivities $(d e \geqslant 99 \%)$. And the absolute configuration of optically active ferrocenylamines $[(R, R)-\mathbf{3 a} ;(S, S)-3 \mathbf{b}]$ was determined by X-ray diffraction. ${ }^{[7]}$

Suitable single crystals of compounds $(R, R)-\mathbf{3 a}$ and $(S, S)$-3b were developed from $n$-hexane. The X-ray crystal structure analysis of $(R, R)$-3a (Figure 1) and $(S, S)$-3b (Figure 2) showed clearly that the absolute configuration of the new stereogenic center was $R$ in $(R, R)-\mathbf{3 a}$ and $S$ in $(S, S)-\mathbf{3 b}$. These results suggested that the prochiral ferrocenylketimines $\mathbf{2 a}, \mathbf{2 b}$ were successfully transformed into chiral secondary amines with high diastereoselectivity. Meanwhile, the substituted cyclopentadienyl and benzene ring are in cis arrangement, the value of torsion angle for $\mathrm{C}(11)-\mathrm{N}(1)-\mathrm{C}(13)-$ $\mathrm{C}(14)$ is $56.3^{\circ}[(R, R)-\mathbf{3 a}]$ and $55.3^{\circ}[(S, S)-\mathbf{3 b}]$, respectively. The two cyclopentadienyl rings are nearly parallel, with a deviation from an ideal parallel conformation giving the dihedral angles of $1.3^{\circ}$ for $(R, R)-3 \mathbf{a}$ and $1.7^{\circ}$ for $(S, S)-\mathbf{3 b}$.

Removal of the chiral auxiliary is generally accomplished by hydrogenolysis with Pearlman's catalyst to give the corresponding amine. ${ }^{[5 \mathrm{a}]}$ Normally, 20\% $\mathrm{Pd}(\mathrm{OH})_{2}$ on carbon and $344.75-379.22 \mathrm{kPa}$ of hydrogen were required. The major drawback of this protocol is the cost associated with the high palladium metal loading and undergoing under hydrogen pressure. As an economical and safe method, the compounds $(R, R)-\mathbf{3 a}$, $(R, R)-3 \mathbf{b}$ underwent cleavage of the $\alpha$-methylbenzyl moiety without loss of enantiomeric purity in the presence of ammonium formate as the hydrogen donor and $5 \% \mathrm{Pd} / \mathrm{C}$ as the catalyst, giving $(R)-\mathbf{4 a}(90 \%$ yield, $\geqslant 99 \% e e)$ and $(R)-\mathbf{4 b}(92 \%$ yield, $\geqslant 99 \%$ ee $)$, respectively (Scheme 1). This method took the advantages of

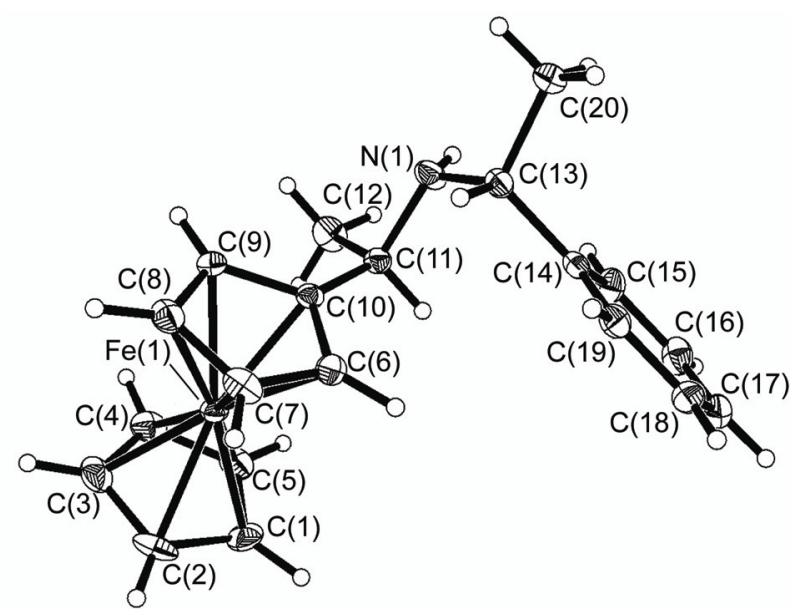

Figure 1 Molecular structure of compound $(R, R)-3 \mathbf{a}$. Selected bond lengths $(\AA)$ and angles $\left({ }^{\circ}\right): \mathrm{C}(10)-\mathrm{C}(11) 1.498(6), \mathrm{C}(11)-$ $\mathrm{N}(1)$ 1.464(6), $\mathrm{N}(1)-\mathrm{C}(13)$ 1.445(5); $\mathrm{C}(10)-\mathrm{C}(11)-\mathrm{N}(1)$ 109.8(4), C(11)-N(1)-C(13) 118.9(4), N(1)-C(13)-C(14) 115.1(4).

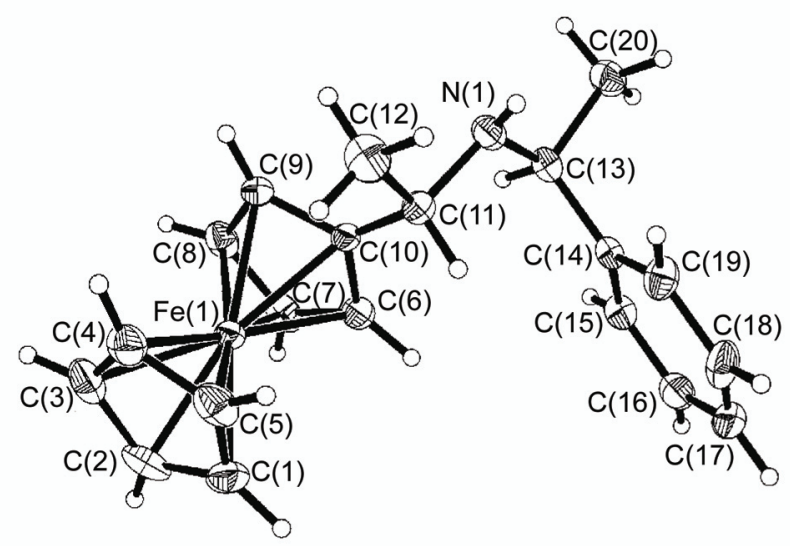

Figure 2 Molecular structure of compound $(S, S)-\mathbf{3 b}$. Selected bond lengths $(\AA)$ and angles $\left({ }^{\circ}\right)$ : $\mathrm{C}(10)-\mathrm{C}(11)$ 1.481(7), $\mathrm{C}(11)-$ $\mathrm{N}(1) 1.456(7), \mathrm{N}(1)-\mathrm{C}(13) 1.455(6) ; \mathrm{C}(10)-\mathrm{C}(11)-\mathrm{N}(1)$ 110.7(4), $\mathrm{C}(11)-\mathrm{N}(1)-\mathrm{C}(13)$ 118.6(4), N(1)-C(13)-C(14) 115.0(5).

Scheme 1

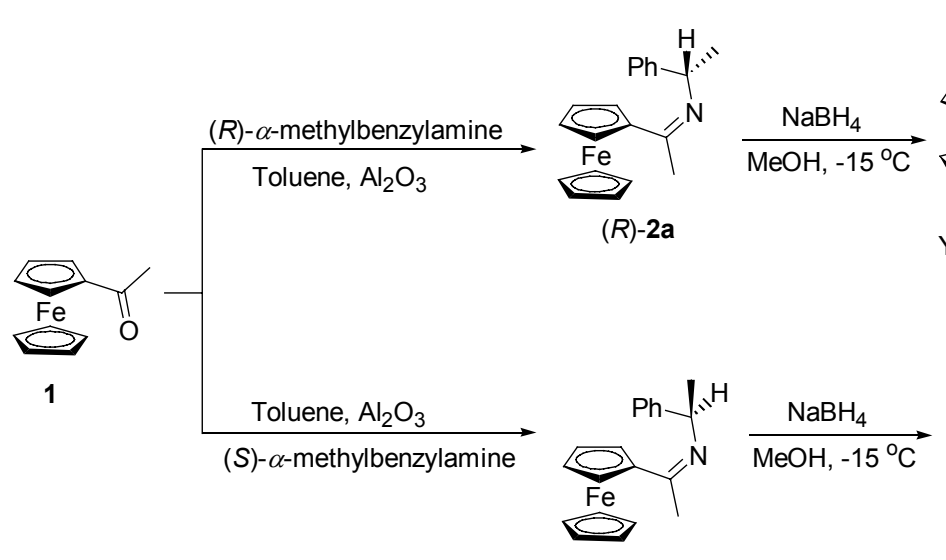

$(S)-\mathbf{a}$

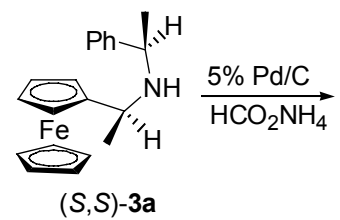

Yield $85 \%$, de $\geq 99 \%$

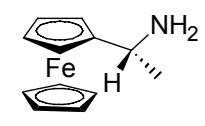

$(R)-4 a$

Yield $90 \%$, ee $\geq 99 \%$ 
safety and mild reaction conditions.

Next we turned our attention to more prochiral ferrocenylketimines, the results are presented in Table 1. $(R)$-5a gave a mixture of ferrocenylamines $(R, R)-6 \mathbf{a}$ and $(R, S)-6 \mathbf{a}$ in $85 \%$ yield with $68 \%$ de (Table 1 , Entry 1$)$, which was determined by ${ }^{1} \mathrm{H}$ NMR spectrum. There were two well-separated signals of methine protons at the new stereocenter position $(R, R: \delta 3.02 ; R, S: \delta 3.14)$. We failed to isolate these two diastereomers by silica gel chromatography. Reduction of ferrocenylketimine $(R)-5 \mathbf{b}$ gave the mixture $\mathbf{6 b}$ in $56 \%$ yield with $74 \%$ de (Table 1, Entry 2). These results suggested that the in-

Table 1 Hydride reduction of ketimines $(R)-5$

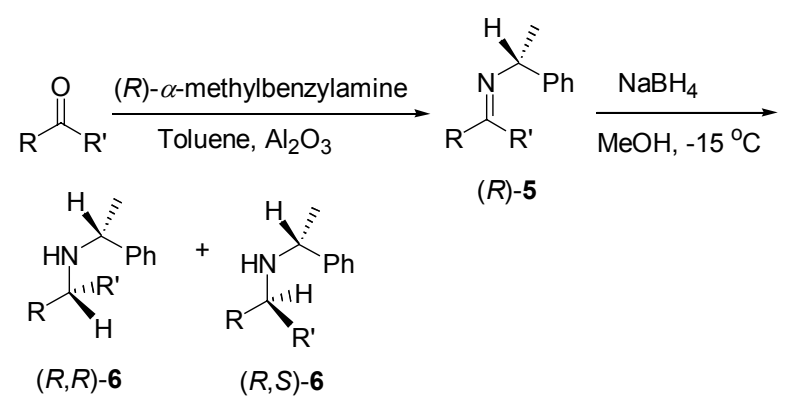

a: $\mathrm{R}=$ ferrocenyl, $\mathrm{R}^{\prime}=\mathrm{CH}_{2} \mathrm{CH}_{3} ;$ b: $\mathrm{R}=$ ferrocenyl, $\mathrm{R}^{\prime}=\mathrm{CH}_{2} \mathrm{CH}_{2} \mathrm{CH}_{3}$; c: $\mathrm{R}=$ 3-nitrophenyl, $\mathrm{R}^{\prime}=\mathrm{CH}_{3} ; \mathbf{d}: \mathrm{R}=$ 2-naphthyl, $\mathrm{R}^{\prime}=\mathrm{CH}_{3}$;

e: $\mathrm{R}=2$-furyl, $\mathrm{R}^{\prime}=\mathrm{CH}_{3} ;$ f: $\mathrm{R}=$ 2-thienyl, $\mathrm{R}^{\prime}=\mathrm{CH}_{3}$

\begin{tabular}{cccccc}
\hline Entry & $\mathrm{R}$ & $\mathrm{R}^{\prime}$ & Product & \multicolumn{2}{c}{$d e / \%$ Yield $\%$} \\
\hline 1 & Ferrocenyl & $\mathrm{CH}_{2} \mathrm{CH}_{3}$ & $(R, R)-\mathbf{6 a} /(R, S)-\mathbf{6 a}$ & 68 & 85 \\
2 & Ferrocenyl & $\mathrm{CH}_{2} \mathrm{CH}_{2} \mathrm{CH}_{3}(R, R)-\mathbf{6 b} /(R, S)$-6b & 74 & 56 \\
3 & 3-Nitrophenyl & $\mathrm{CH}_{3}$ & $(R, R)-\mathbf{6 c} /(R, S)-\mathbf{6 c}$ & 64 & 88 \\
4 & 2-Naphthyl & $\mathrm{CH}_{3}$ & $(R, R)-\mathbf{6 d} /(R, S)-\mathbf{6 d}$ & 58 & 91 \\
5 & 2-Furyl & $\mathrm{CH}_{3}$ & $(R, R)-\mathbf{6 e} /(R, S)$-6e & 62 & 93 \\
6 & 2-Thienyl & $\mathrm{CH}_{3}$ & $(R, R)-\mathbf{6 f} /(R, S)-\mathbf{6 f}$ & 80 & 90 \\
\hline
\end{tabular}

corporation of the bulky alkyl group made the yield and diastereoselectivity decreases.

This procedure was extended to the aryl- and heteroaryl ketimines, and afforded the chiral amines in high yields with moderate to good stereoselectivity of $58 \%-80 \%$ de (Table 1, Entries 3-6). The best result was obtained in the thienyl ketimine reduction $[(R)-\mathbf{5 f}$, Table 1, Entry 6], providing the amine $6 \mathbf{f}$ in $90 \%$ yield with $80 \%$ de.

$1,1^{\prime}$-Bis-( $\alpha$-aminoethyl)ferrocene was employed as powerful synthetic precursors for the ferrocene derivatives in asymmetric catalysis. ${ }^{[8]}$ It was prepared by the enantioselective reduction of the corresponding 1,1'-diacylferrocene (CBS reduction) using an excess of nucleophile and oxazaborolidine as ligand in the literature. ${ }^{[2 a, 9]}$ However, the optically active oxazaborolidine is much more costly. ${ }^{[10]}$ Herein, we were pleased to find that the protocol mentioned above was applied to synthesize the chiral 1,1'-bis-( $\alpha$-aminoethyl)ferrocene (Scheme 2). The 1,1'-diacylferrocene was reacted with $(R)$ and $(S)$ - $\alpha$-methylbenzylamine in toluene in the presence of $\mathrm{Al}_{2} \mathrm{O}_{3}$, affording the ketimines $\mathbf{8 a}, \mathbf{8 b}$, which were used for next step without purification. Reduction with sodium borohydride at $-15{ }^{\circ} \mathrm{C}$ in dry methanol provided the corresponding chiral secondary amines 9a, 9b in good yields (9a, 83\% and 9b, 84\%) and excellent stereoselectivity. For $(R, R, R, R)-\mathbf{9 a}$, the diastereomeric excess was determined by ${ }^{1} \mathrm{H}$ NMR spectra $(98 \%$ de). However, the diastereoselectivity decreased $(82 \% d e)$ at the higher reaction temperature $(0$ $\left.{ }^{\circ} \mathrm{C}\right)$. Then cleavage of chiral auxiliary of $\mathbf{9 a}, 9 \mathbf{b}$ was accomplished by $5 \% \mathrm{Pd} / \mathrm{C}$ in the presence of ammonium formate to yield the chiral 1,1'-bis-( $\alpha$-aminoethyl)ferrocene 10a and $\mathbf{1 0 b}$.

Compared with the report in the literature, ${ }^{[5 a]}$ for example, the reduction of $(R)-\mathbf{2 a}$ at $25{ }^{\circ} \mathrm{C}$ gave the

\section{Scheme 2}

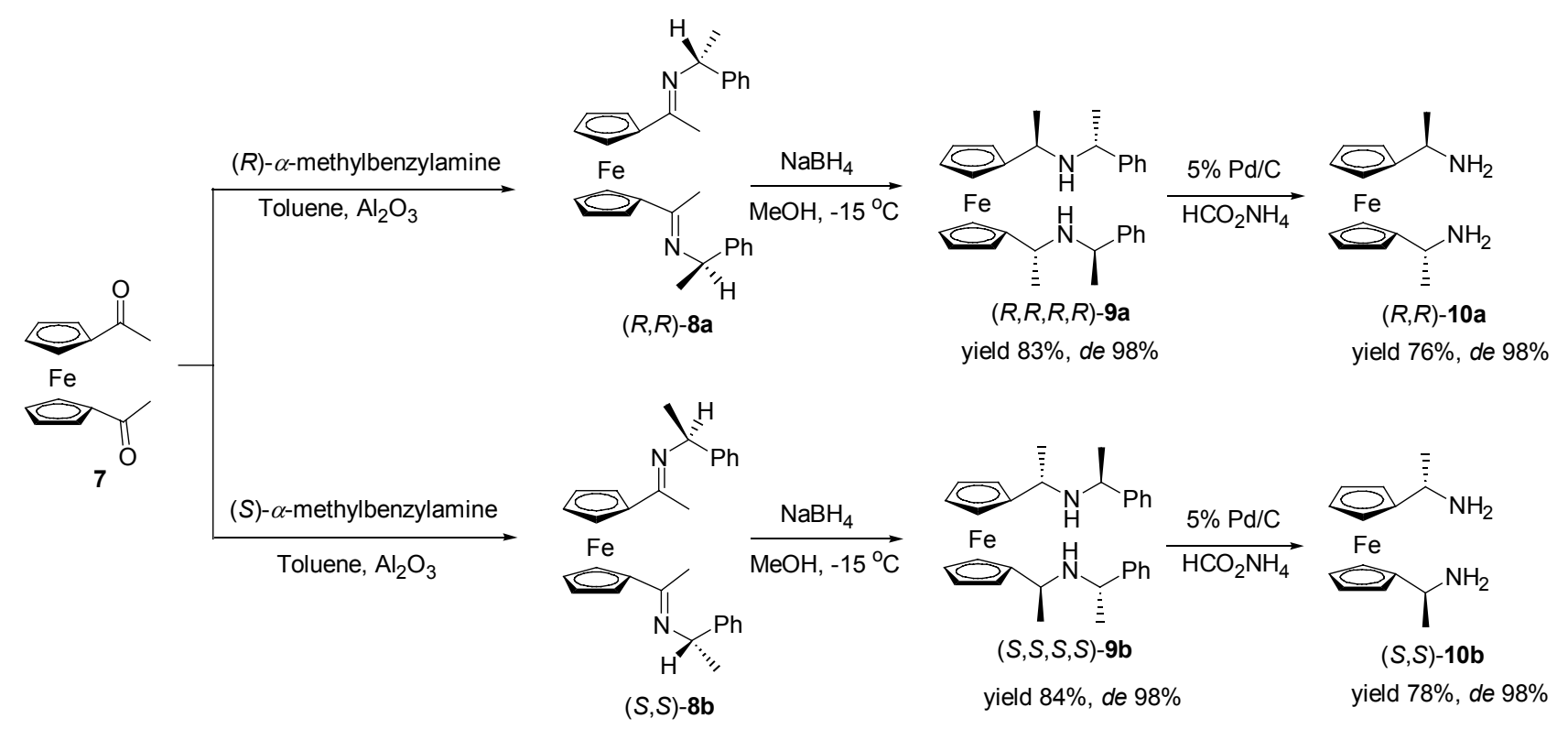


corresponding amine $(R, R)-\mathbf{3 a}$ with $80 \%$ de, the enhancement in selectivity for $\mathrm{NaBH}_{4}$ in this paper may be caused by the lower reactivity at low temperature. Under the same reaction conditions, the reduction of ferrocenylketimine $(R)$-2a with sodium borohydride gave higher stereoselectivity $(99 \% d e)$ than that of ferrocenylketimines $(R)-5 \mathbf{a}(68 \% d e)$ and $(R)-5 \mathbf{b}(74 \% d e)$, respectively. This may be ascribed to the bulkier alkyl substituent attached to the carbonyl group in $(R)-5 \mathbf{a}$ and $(R)-5 \mathbf{b}$ than methyl group in $(R)-\mathbf{2 a}$, which could not fulfil the $\mathrm{BH}_{4}^{-}$group under the plane, and reduce the stereoselectivity. On the other hand, we also found that $(R)-\mathbf{5} \mathbf{c}-(R)-\mathbf{5 f}$ gave the corresponding amines in quantitative yield with moderate diastereoselectivity, where the ferrocenyl moiety was replaced by the aryl or heteroaryl ring. These results suggest that different from the ferrocenyl group, the aryl or hetaryl moiety could not fulfill a spatial requirement to shield the $\pi$-plane which consisted of the imine moiety and aryl or hetaryl ring.

\section{Conclusions}

In summary, a simple and efficient method has been developed for the synthesis of chiral mono- and bisferrocenylamines via hydride addition to the ferrocenylketimines with high stereoselectivity, starting from cheap and commercial available optical $\alpha$-methylbenzylamine. Meanwhile, cleavage of the $\alpha$-methylbenzyl moiety could be performed in high yield using a 5\% palladium/carbon catalyst in the presence of ammonium formate as hydrogen donor.

\section{Acknowledgement}

We are grateful to the National Natural Science Foundation of China (Nos. 20972139, 21102133) and the Natural Science Foundation of Henan Province (No.
082300423201) for the financial support to this research.

\section{References}

[1] (a) Togni, A.; Hayashi, T. Ferrocenes: Homogeneous Catalysis, Organic Synthesis, Materials Science, VCH, Weinheim, 1995; (b) Stepnicka, P. Ferrocenes: Ligands, Materials and Biomolecules, John Wiley \& Sons, Ltd, West Sussex, England, 2008.

[2] (a) Arrayas, P. G.; Adrio, J.; Carretero, J. C. Angew. Chem., Int. Ed. 2006, 45, 7674; (b) Atkinson, R. C. J.; Gibson, V. C.; Long, N. J. Chem. Soc. Rev. 2004, 33, 313; (c) Dai, L. X.; Tu, T.; You, S. L.; Deng, W. P.; Hou, X. L. Acc. Chem. Res. 2003, 36, 659; (d) Chiral Ferrocenes in Asymmetric Catalysis, Eds.: Dai, L. X.; Hou, X. L., Wiley-VCH, Weinheim, 2010.

[3] Richards, C. J.; Locke, A. J. Tetrahedron: Asymmetry 1998, 9, 2377.

[4] (a) Fukuda, T.; Takehara, A.; Haniu, N.; Iwao, M. Tetrahedron Asymmetry 2000, 11, 4083; (b) Enders, D.; Lochtman, R.; Raabe, G. Synlett 1996, 126; (c) Zhang, H. Q.; Zhou, Z. M.; Fang, M. Lett. Org. Chem. 2006, 3, 802; (d) Matsumoto, Y.; Ohno, A.; Lu, S. J.; Hayashi, T.; Oguni, N.; Hayashi, M. Tetrahedron: Asymmetry 1993, 4, 1763.

[5] (a) David, D. M.; Kane-Maguire, L. A. P.; Pyne, S. G. J. Chem. Soc., Chem. Commun. 1990, 888; (b) Glorian, G.; Maciejewski, L.; Brocard, J.; Agbossou, F. Tetrahedron: Asymmetry 1997, 8, 355; (c) Bhattacharyya, S. Synth. Commun. 1994, 24, 2713; (d) Bhattacharyya, S. Synlett 1994, 1029; (e) Periasamy, M.; Thirumalaikumar, M. J. Organomet. Chem. 2000, 609, 137.

[6] Kim, T. J.; Lee, H. Y.; Ryu, E. S.; Park, D. K.; Cho, C. S.; Shim, S C.; Jeong, J. H. J. Organomet. Chem. 2002, 649, 258

[7] Details of the X-ray structure analyses of $(R, R)-\mathbf{3 a}$ and $(S, S)$-3b were made on a RAXIS-IV imagine plate area detector with a graphite monochromated Mo $\mathrm{K} \alpha$ radiation $(\lambda=0.71073 \AA)$. The structures were solved by direct methods and expanded using Fourier techniques and refined by full-matrix least-squares methods. CCDC-293912 and CCDC-715334 contain the supplementary crystallographic data for this paper.

[8] (a) Ballistreri, F. P.; Patti, A.; Pedotti, S.; Tomaselli, G. A.; Toscano, R. M. Tetrahedron: Asymmetry 2007, 18, 2377; (b) Schwink, L.; Knochel, P. Chem. Eur. J. 1998, 4, 950.

[9] Corey, E. J.; Helal, C. J. Angew. Chem., Int. Ed. 1998, 37, 1986.

[10] Schwink, L.; Knochel, P. Tetrahedron Lett. 1996, 37, 25. 